\title{
Unmasking Snake Venom of Bothrops leucurus: Purification and Pharmacological and Structural Characterization of New PLA 2 Bleu TX-III
}

\author{
Fábio André Marangoni, ${ }^{1}$ Luis Alberto Ponce-Soto, ${ }^{2}$ \\ Sergio Marangoni, ${ }^{2}$ and Elen Cristina Teizem Landucci ${ }^{1}$ \\ ${ }^{1}$ Department of Pharmacology, Faculty of Medical Sciences, State University of Campinas, 13083-970 Campinas, SP, Brazil \\ ${ }^{2}$ Department of Biochemistry, Institute of Biology, State University of Campinas, 13083-970 Campinas, SP, Brazil
}

Correspondence should be addressed to Luis Alberto Ponce-Soto; poncesoto@yahoo.com.ar

Received 4 September 2012; Revised 31 October 2012; Accepted 6 November 2012

Academic Editor: Laura Leiva

Copyright (C) 2013 Fábio André Marangoni et al. This is an open access article distributed under the Creative Commons Attribution License, which permits unrestricted use, distribution, and reproduction in any medium, provided the original work is properly cited.

Bleu TX-III was isolated from Bothrops leucurus snake venom on one-step analytical chromatography reverse phase HPLC, was homogeneous on SDS-PAGE, and was confirmed by Q-Tof Ultima API ESI/MS (TOF MS mode) mass spectrometry in $14243.8 \mathrm{Da}$. Multiple alignments of Bleu TX-III show high degree of homology with basic PLA 2 myotoxins from other Bothrops venoms. Our studies on local and systemic myotoxicity "in vivo" reveal that Bleu TX-III is myotoxin with local but not systemic action due to the decrease in the plasmatic CK levels when Bleu TX-III is administrated by intravenous route in mice (dose $1 \mathrm{and} 5 \mu \mathrm{g}$ ). And at a dose of $20 \mu \mathrm{g}$ myotoxin behaves like a local and systemic action. Bleu TX-III induced moderate marked paw edema, evidencing the local increase in vascular permeability. The inflammatory events induced in the mice (I.M.) were investigated. The increase in the levels of IL-1, IL-6, and TNF- $\alpha$ was observed in the plasma. It is concluded that Bleu TX-III induces inflammatory events in this model. The enzymatic phospholipid hydrolysis may be relevant to these phenomena. Bothrops leucurus venom is still not extensively explored, and the knowledge of its toxins separately through the study of structure/function will contribute for a better understanding of its action mechanism.

\section{Introduction}

Snake venom contains a mixture of powerful proteins and peptides that have evolved to be targeted to receptors, ion channels, or enzymes [1], in addition to some carbohydrates, nucleosides, lipids, and metal ions, whose functions are not all known $[2,3]$. They interact with a wide variety of mammalian proteins and can disrupt the central and peripheral nervous systems, the blood coagulation cascade, the cardiovascular and neuromuscular systems, and homeostasis in general. These venom proteins act with great precision different toxins recognize different subtypes of certain receptors with only subtle differences and are very biologically active.

Phospholipases $\mathrm{A}_{2}\left(\mathrm{PLA}_{2}\right.$, EC 3.1.1.4) are generally $\mathrm{Ca}^{2+}$ dependent enzymes that catalyze the hydrolysis of the sn-2 fatty acyl bond of glycerophospholipids. Secreted $\mathrm{PLA}_{2} \mathrm{~S}$ are small proteins (14-18 $\mathrm{kDa}$ ) usually containing 5-8 disulfide bonds and possessing a His/Asp dyad required for catalysis. Snake venom $\mathrm{PLA}_{2} \mathrm{~s}$ are classified into groups I or II, based on their sequence and mode of disulphide pairings. Group I $\mathrm{PLA}_{2} \mathrm{~S}$ are found in the venoms of Elapidae snakes, whereas group II $\mathrm{PLA}_{2} \mathrm{~s}$ are present in the venoms of Viperidae snakes [4]. The group II is further divided into two main subgroups: Asp49 and Lys49 ( PLA $_{2}$ homologues) variants. In the latter, the aspartic acid residue at position 49 , critically involved in calcium binding and essential for catalytic activity, is replaced by lysine. Due to this and other critical substitutions, the Lys49 PLA $_{2}$ s cannot bind calcium efficiently and are considered to be enzymatically inactive $[5,6]$. Although catalytic activity has been shown to play a role in the toxic actions of some venom $\mathrm{PLA}_{2} \mathrm{~s}$, it is not essential in the case of 
Lys49 $\mathrm{PLA}_{2} \mathrm{~s}$, which use nonenzymatic mechanisms to alter membrane homeostasis [6].

Several $\mathrm{PLA}_{2}$ s have been identified from Bothrops leucurus venom including one acidic [7], one basic phospholipase $\mathrm{A}_{2}$ and phospholipase $\mathrm{A}_{2}$ homologous K49 [8]. This diversity of $\mathrm{PLA}_{2}$, found in the venom of Bothrops leucurus, agrees with studies that show marked ontogenetic and individual venom variations [1].

In the present work, a new basic PLA $_{2}$ (Bleu TX-III) from the venom of Bothrops leucurus has been isolated and characterized, in order to obtain insights into its possible biological roles and its relevance to the pathophysiology of envenomings by this species in the north-eastern Brazil.

\section{Material and Methods}

2.1. Reverse Phase HPLC. The $\mathrm{PLA}_{2}$ (Bleu TX-III) from Bothrops leucurus snake venom was purified by reverse phase HPLC according to method described by Ponce-Soto et al. [9]. Briefly, $5 \mathrm{mg}$ of whole venom was dissolved in $100 \mu \mathrm{L}$ of buffer $\mathrm{A}\left(0.1 \%\right.$ TFA) and $150 \mu \mathrm{L} \mathrm{NH}_{4} \mathrm{HCO}_{3} 50 \mathrm{mM}$ and centrifuged at $4500 \mathrm{~g}$, and the supernatant was then applied on the analytical reverse phase HPLC $\mu$-Bondapack C-18, previously equilibrated with buffer A for $15 \mathrm{~min}$. The elution of the protein was then conducted using a linear gradient of buffer B (66.5\% Acetronitrile in buffer A), and the chromatographic run was monitored at $280 \mathrm{~nm}$ of absorbance. After elution the fraction was lyophilized and stored at $40^{\circ} \mathrm{C}$.

2.2. Electrophoresis. Tricine SDS-PAGE in a discontinuous gel and buffer system was used to estimate the molecular mass of the proteins, under reducing and nonreducing conditions [10].

2.3. $P L A_{2}$ Activity. $\mathrm{PLA}_{2}$ activity was measured using the assay described [11] modified for 96-well plates [12]. The standard assay mixture contained $200 \mu \mathrm{L}$ of buffer

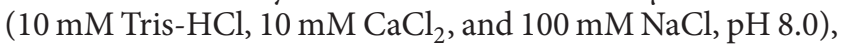
$20 \mu \mathrm{L}$ of substrate $(3 \mathrm{mM}), 20 \mu \mathrm{L}$ of water and $20 \mu \mathrm{L}$ of $\mathrm{PLA}_{2}$ $(1 \mathrm{mg} / \mathrm{mL})$ in a final volume of $260 \mu \mathrm{L}$. After adding $\mathrm{PLA}_{2}$ (Bleu TX-III) from Bothrops leucurus $(20 \mu \mathrm{g})$, the mixture was incubated for up to $40 \mathrm{~min}$ at $37^{\circ} \mathrm{C}$, with the reading of absorbance at intervals of $10 \mathrm{~min}$. The enzyme activity, expressed as the initial velocity of the reaction $\left(V_{o}\right)$, was calculated based on the increase of absorbance after $20 \mathrm{~min}$. All assays were done in triplicate, and the absorbances at $425 \mathrm{~nm}$ were measured with a VersaMax 190 multiwell plate reader (Molecular Devices, Sunnyvale, CA, USA).

2.4. Amino Acid Analysis. Amino acid analysis was performed on a Pico-Tag Analyzer (Waters Systems) as described [13]. The $\mathrm{PLA}_{2}$ (Bleu TX-III) from Bothrops leucurus, sample $(30 \mu \mathrm{g})$, was hydrolyzed at $105^{\circ} \mathrm{C}$ for $24 \mathrm{~h}$, in $6 \mathrm{M} \mathrm{HCl}$ (Pierce sequencing grade) containing $1 \%$ phenol (w/v). The hydrolyzates were reacted with $20 \mu \mathrm{L}$ of derivatization solution (ethanol:triethylamine: water: phenylisothiocyanate, $7: 1: 1: 1, \mathrm{v} / \mathrm{v})$ for $1 \mathrm{~h}$ at room temperature, after which the PTC-amino acids were identified and quantified by HPLC, by comparing their retention times and peak areas with those from a standard amino acid mixture.

2.5. Mass Spectrometry. An aliquot $(4.5 \mu \mathrm{L})$ of the modified proteins was inject in C18 $(100 \mu \mathrm{m} \times 100 \mathrm{~mm})$ RP-UPLC (nanoAcquity UPLC, Waters) coupled with nanoelectrospray tandem mass spectrometry on a Q-Tof Ultima API mass spectrometer (MicroMass/Waters) at a flow rate of $600 \mathrm{nl} / \mathrm{min}$. The gradient was $0-50 \%$ acetonitrile in $0.1 \%$ formic acid over $45 \mathrm{~min}$. The instrument was operated in MS continuum mode, and the data acquisition was from $\mathrm{m} / z 100-3.000$ at a scan rate of $1 \mathrm{~s}$ and an interscan delay of $0.1 \mathrm{~s}$. The spectra were accumulated over about 300 scans and the multiple charged data by the mass spectrometer on the $m / z$ scale were converted to the mass (molecular weight) scale using Maximum Entropy-based software supplied with Masslynx 4.1 software package. The processing parameters were output mass range 6.000-20.000 Da at a "resolution" of $0.1 \mathrm{Da} / \mathrm{channel}$; the simulated isotope pattern model was used with the spectrum blur width parameter set to $0.2 \mathrm{Da}$, the minimum intensity ratios between successive peaks were $20 \%$ (left and right). The deconvoluted spectrum was then smoothed $(2 \times 3$ channels, Savitzky Golay smooth) and the mass centroid values obtained using $80 \%$ of the peak top and a minimum peak width at half height of 4 channels.

2.6. Myotoxic Activity. Groups of four Swiss mice (18-20 g) received an intramuscular (i.m.) or an intravenous (i.v.) injection of variable amounts of $\mathrm{PLA}_{2}$ (Bleu TX-III) from Bothrops leucurus in $100 \mu \mathrm{L}$ of PBS, in the gastrocnemius. A control group received $100 \mu \mathrm{L}$ of PBS. At different intervals of time $(2,4,6,9$, and $24 \mathrm{~h})$ blood was collected from the tail into heparinized capillary tubes, and the plasma creatine kinase (CK; EC 2.7.3.2) activity was determined by a kinetic assay (Sigma 47-UV). Activity was expressed in U/L, one unit defined as the phosphorylation of $1 \mu \mathrm{mol}$ of creatine $/ \mathrm{min}$ at $25^{\circ} \mathrm{C}$.

2.7. Edema-Forming Activity. The ability of $\mathrm{PLA}_{2}$ (Bleu TXIII) from Bothrops leucurus to induce edema was studied in groups of five Swiss mice $(18-20 \mathrm{~g}) .50 \mu \mathrm{L}$ of phosphatebuffered saline (PBS; 0.12 M NaCl, 0.04 M sodium phosphate, $\mathrm{pH} 7.2)$ with venom $(10 \mu \mathrm{g} / \mathrm{paw})$ was injected in the subplantar region of the right footpad. The control group received an equal volume of PBS alone. The swelling of the paw was measured at $0.5,1,3,6,9$, and $24 \mathrm{~h}$ after administration. Edema was expressed as the percentage increased in the volume of the treated group to that of the control group at each time interval.

2.8. Cytokines. The levels of cytokines IL-6 and IL-1 in the serum from BALB/c mice were assayed by a twosite sandwich enzyme-like immunosorbent assay (ELISA) as described [14]. In brief, ELISA plates were coated with $100 \mu \mathrm{L}(1 \mu \mathrm{g} / \mathrm{mL})$ of the monoclonal antibodies anti-IL6 and anti-IL-1. In $0.1 \mathrm{M}$ sodium carbonate buffer $(\mathrm{pH}$ 8.2) and incubated for 6 hours at room temperature. The 
wells were then washed with $0.1 \%$ phosphate-buffered saline (PBS/Tween-20) and blocked with $100 \mu \mathrm{L}$ of $10 \%$ fetal calf serum (FCS) in PBS for 2 hours at room temperature. After washing, duplicate sera samples of $50 \mu \mathrm{L}$ were added to each well. After 18 hours of incubation at $4^{\circ} \mathrm{C}$, the wells were washed and incubated with $100 \mu \mathrm{L}(2 \mu \mathrm{g} / \mathrm{mL})$ of the biotinylated monoclonal antibodies anti-IL- 6 and anti-IL-1 as second antibodies for 45 minutes at room temperature. After a final wash, the reaction was developed by the addition of orthophenyldiamine (OPD) to each well. Optical densities were measured at $405 \mathrm{~nm}$ in a microplate reader. The cytokine content of each sample was read from a standard curve established with the appropriate recombinant cytokines (expressed in picograms per millilitre). The minimum levels of each cytokine detectable in the conditions of the assays were $10 \mathrm{pg} / \mathrm{mL}$ for IL-6 and IL- 1 .

To measure the cytotoxicity of TNF- $\alpha$ present in the serum from BALB/c mice, a standard assay with L-929 cells, a fibroblast continuous cell line was used as described previously [15]. The percentage cytotoxicity was calculated as follows:

$$
\left(A_{\text {control }}-\frac{A_{\text {sample }}}{A_{\text {control }}}\right) \times 100 .
$$

Titres were calculated as the reciprocal of the dilution of the sample in which $50 \%$ of the cells in the monolayer were lysed. TNF- $\alpha$ activity is expressed as units $/ \mathrm{mL}$, estimated from the ratio of a 50\% cytotoxic dose of the test to that of the standard mouse recombinant TNF- $\alpha$.

2.9. Statistical Analyses. Results were reported as mean \pm SEM. The significance of differences among means was assessed by analysis of variance followed by Dunnett's test when several experimental groups were compared with the control group. Differences were considered statistically significant if $P<0.05$.

\section{Results}

The elution profile of Bothrops leucurus venom following RP-HPLC performed on a C18 column showed thirteen fractions (1-12) (Figure 1(a)). The five eluted peaks were screened for $\mathrm{PLA}_{2}$ activity. Only the fraction labeled in Figure 1(a) presented $\mathrm{PLA}_{2}$ activity, which was eluted with 59\% of buffer B. This peak was further purified by the same chromatography system used in the first fractionation step (RP-HPLC). The result of the repurification showed the presence of only one peak, named Bleu TX-III (Figure 1(a) inserted).

The Q-Tof Ultima API ESI/MS (TOF MS mode) mass spectrometry analysis confirmed the homogeneity of the fraction Bleu TX-III and determined the exact molecular mass of 14243, $4297 \mathrm{Da}$ (Figure 1(b)). This value of molecular mass was used in calculating the molar concentrations of toxin used in the experiments described below.

The amino acid composition determined was $\mathrm{D} / 11, \mathrm{~T} / 9$, $\mathrm{S} / 7, \mathrm{E} / 9, \mathrm{P} / 4, \mathrm{G} / 11, \mathrm{~A} / 5, \mathrm{C} / 14, \mathrm{~V} / 4, \mathrm{M} / 3, \mathrm{I} / 5, \mathrm{~L} / 7, \mathrm{Y} / 11, \mathrm{~F} / 5$, $\mathrm{K} / 7, \mathrm{H} / 3$ e $\mathrm{R} / 10$, W/Not determined.
TABLE 1: Sequence obtained by ESI-MS/MS based on the alkylated tryptic peptides derived. The peptide were separated and sequenced by mass spectrometry.

\begin{tabular}{lccc}
\hline $\begin{array}{l}\text { Residue } \\
\text { Number }\end{array}$ & $\begin{array}{c}\text { Mass }(\mathrm{Da}) \\
\text { expected }\end{array}$ & Amino acid sequence & $\begin{array}{c}\text { Mass (Da) } \\
\text { calculated }\end{array}$ \\
\hline $1-11$ & 1377.6510 & DLWQFGKMILK & 1377.7479 \\
$8-15$ & 918.4353 & MILKETGK & 918.5208 \\
$43-53$ & 1504.4404 & CCFVHDCCYGK & 1504.5356 \\
$61-68$ & 1046.4846 & TDRYSYSR & 1046.4781 \\
$69-82$ & 1520.6066 & ENGDVVCGGDDPCK & 1520.5872 \\
$98-106$ & 1110.4915 & DNKDTYDIK & 1110.5193 \\
$107-113$ & 933.4279 & YWFYGAK & 933.4385 \\
\hline
\end{tabular}

The PLA $\mathrm{P}_{2}$ activity was examined in the Bothrops leucurus venom and in Bleu TX-III using the synthetic substrate 4-nitro-3 (octanoyloxy) benzoic. The $\mathrm{PLA}_{2}$ activity was higher in Bleu TX-III $(16,22 \pm 0,5268 \mathrm{nmols} / \mathrm{mim} / \mathrm{mg})$ and P4 (b/D-PLA $\left.{ }_{2}\right) \quad(15,728 \pm 0,3354 \mathrm{nmols} / \mathrm{mim} / \mathrm{mg})$, when compared with fraction 2 (P3 b/K-PLA $\left.{ }_{2}\right)(2,856$ $\pm 0,464 \mathrm{nmols} / \mathrm{mim} / \mathrm{mg})$, and the whole venom $(3,617 \pm$ 0,4144 $\mathrm{nmols} / \mathrm{min} / \mathrm{mg}$ ) (Figure 1(c)).

The alkylated protein Bleu TX-III was digested separately with trypsin, and the resulting tryptic peptides were fractionated by RP-HPLC. Each peak numbered in the chromatogram (data not shown) was manually collected and lyophilized, and sequencing of the peptide was done by ESI mass spectrometry. Isoleucine and leucine residues were not discriminated in any of the sequences reported since they were indistinguishable in the low-energy CID spectra. Due to the external calibration applied to all spectra, it was also not possible to resolve the $0.036 \mathrm{Da}$ difference between the glutamine and lysine residues, except for the lysine that was deduced based on the cleavage and missed cleavage of the enzyme.

The deduced sequence and measured masses of alkylated peptides of Bleu TX-III are summarized in Table 1; on the basis of sequence determination, 9 peptides were finding in the protein. The sequence of each peptide was then submitted separately to the NCBI database using the protein search program BLAST-p. Using the position matches of the sequenced peptides with homologous proteins present in the database, it was possible to deduce their original position on the unknown protein Bleu TX-III.

The sequence of those proteins returns high homology with the sequence of a phospholipase $A_{2}$ present in the venom of Crotalus scutulatus scutulatus (Mojave rattlesnake) (PA2B_CROSS Accession Number P62023; [16]. The partial Bleu TX-III sequence obtained was then resubmitted to BLAST-p, with the search restricted to Crotalinae snakes. Figure 3 shows the result of BLAST alignment between Bleu TX-III with the phospholipase $\mathrm{A}_{2}$ from human pancreatic (0910150a) [17] and other $\mathrm{PLA}_{2}$ coming from the venom of snakes of the family Viperidae. P62023 Mtx-b PLA 2 of Crotalus scutulatus scutulatus [16]; P0C942_1a LmTX-I de Lachesis muta muta [5] and P0C8M1 BmTX-I of Bothrops moojeni [18]. 


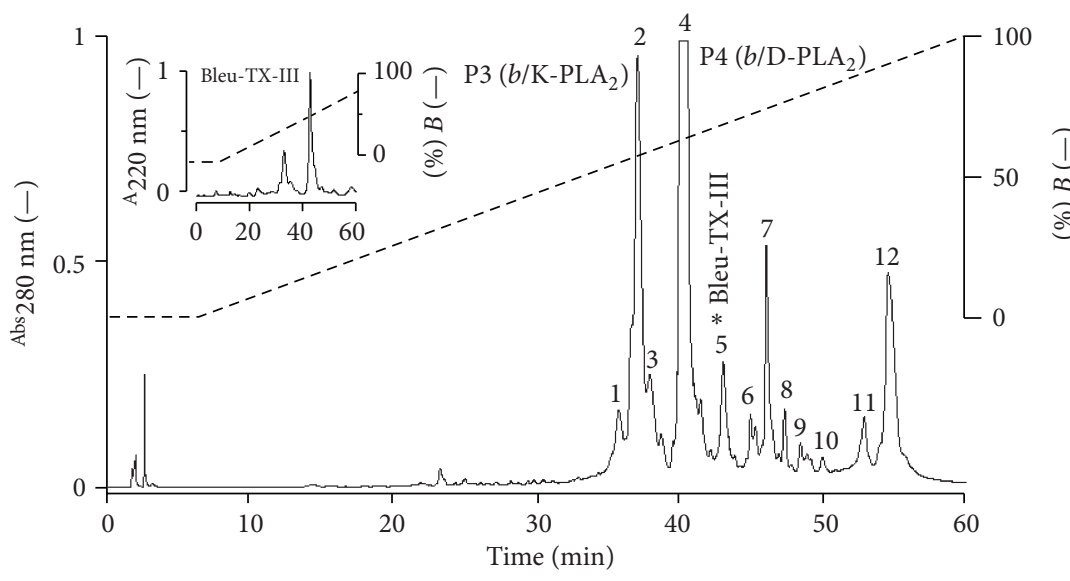

(a)

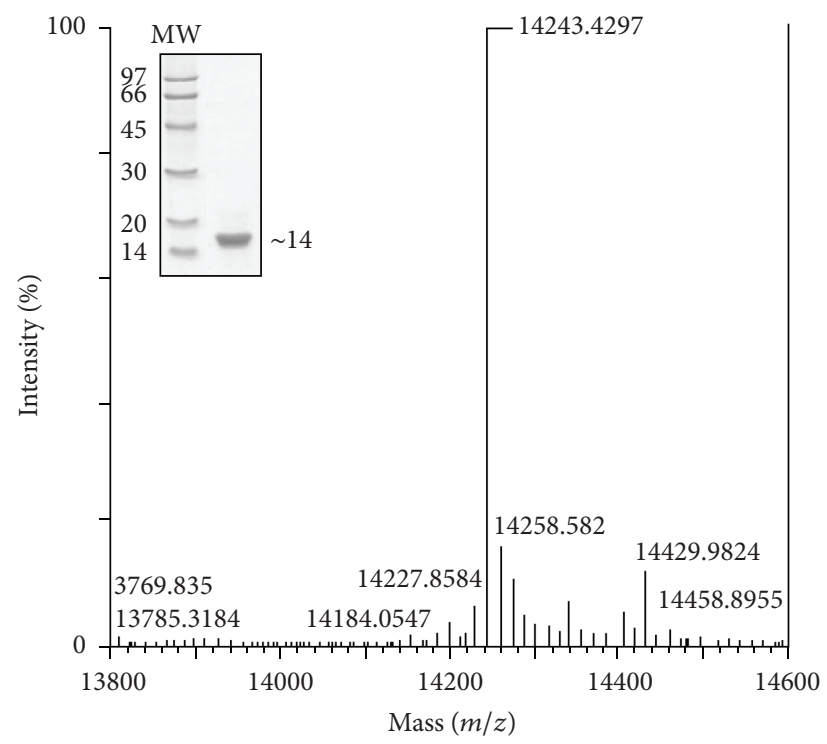

(c)

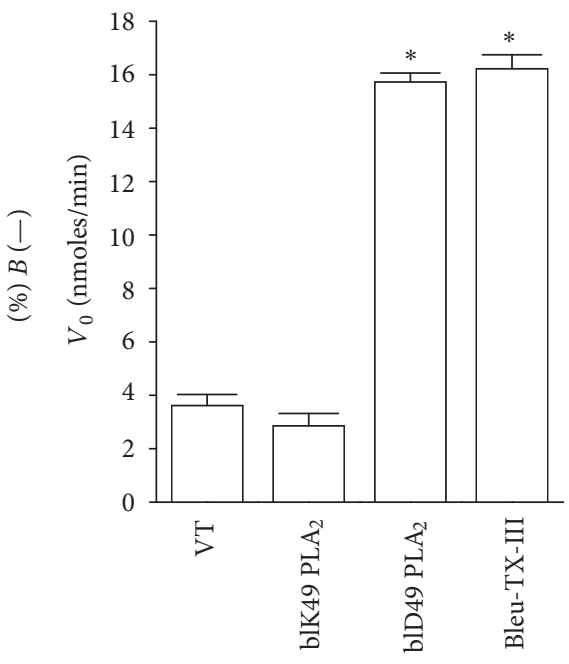

(b)

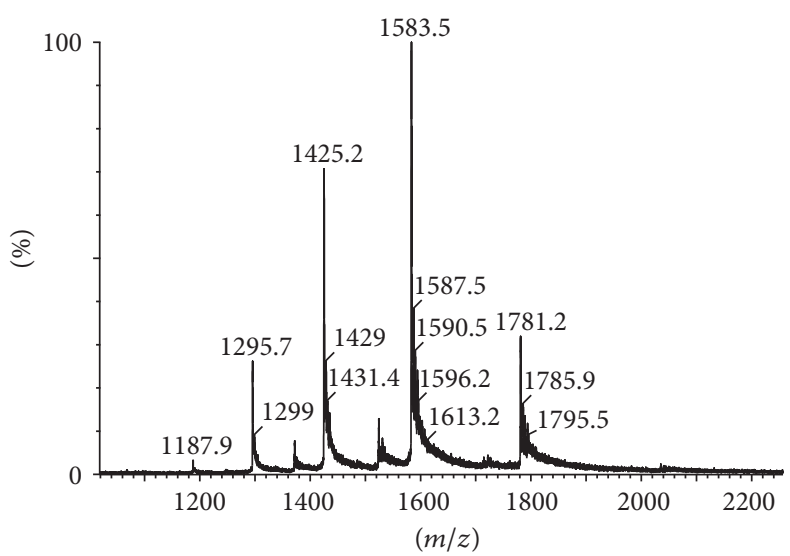

(d)

FIgUre 1: (a) Elution profile of Bothrops leucurus venom by RP-HPLC on a $\mu$-Bondapack C18 column. * Fraction 5 (PLA, Bleu TX-III) contained PLA 2 and myotoxic activity. Insert: rechromatography on RP-HPLC of Bleu TX-III. (b) PLA2 activity of Bothrops leucurus venom, $b / \mathrm{K} 49, b / \mathrm{D} 49$ [8], and PLA 2 Bleu TX-III. The results of all experiments are the mean \pm SEM of three determinations $(P<0.05)$. (c) Mass determination of the native Bleu TX-III by Q-Tof Ultima API ESI/MS (TOF MS mode) mass spectrometry. Insert electrophoretic profile in Tricine SDS-PAGE. (d) Raw electrospray-positive mass spectrum, showing multicharged ions distributions of native Bleu TX-III.

The sequence coverage was high for Bleu TX-III; the protein shared the conserved sequence domains common to this group of proteins, including the 14 cysteines, the calcium-binding site located on Gly30, Gly32, Tyr28, and Asp49, together with the amino acid of active site His48 (SwissProt database http://br.expasy.org/). The tandem mass spectra shown in Figure 2, relative to the peptide eluted in fraction 3 of both digest, having the sequence KCCFVHDCCYG, allow to classify both enzymes as $\mathrm{PLA}_{2}$. In vivo, the Bleu TX-III induced a visible local myotoxic when injected by the i.m. route (Figure 4(a)), but with a regular increase in plasma levels of CK occurred after IV injection in single dose of $20 \mu \mathrm{g}$. Time-course analysis showed a maximum increase in plasma CK 3 hours after i.m. injection, returning to normal by $24 \mathrm{~h}$ (Figure $4(\mathrm{~b}))$.

Bleu TX-III also induced moderate footpad edema, with a MED of $5 \pm 2 \mu \mathrm{g}$, evidencing the local increase in vascular permeability. Edema reached its highest point after $3 \mathrm{~h}$, rapidly returning to basal levels thereafter (Figure 4(c)).

To further analyse and compare the mechanisms of the inflammatory events induced by $\mathrm{PLA}_{2}$ Bleu TX-III, the concentrations of IL-1, IL- 6 , and TNF- $\alpha$ in the plasma were measured. Bleu TX-III caused a marked increase in levels of both IL-1 and IL-6, 1, 3, and 6 hours, peaking at 6 hours 


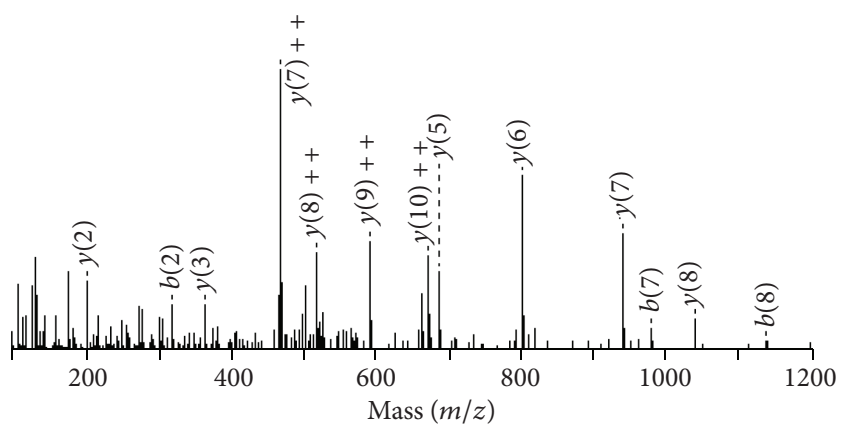

FIGURE 2: MS/MS spectrum of the doubly-charged tryptic ion of $m / z 1504$. Ion of the major sequence-specific $y$-ion serie and of aminor series of the complementing $b$-ions CCFVHDCCYGK, from which the sequence of Bleu TX-III tag was deduced.

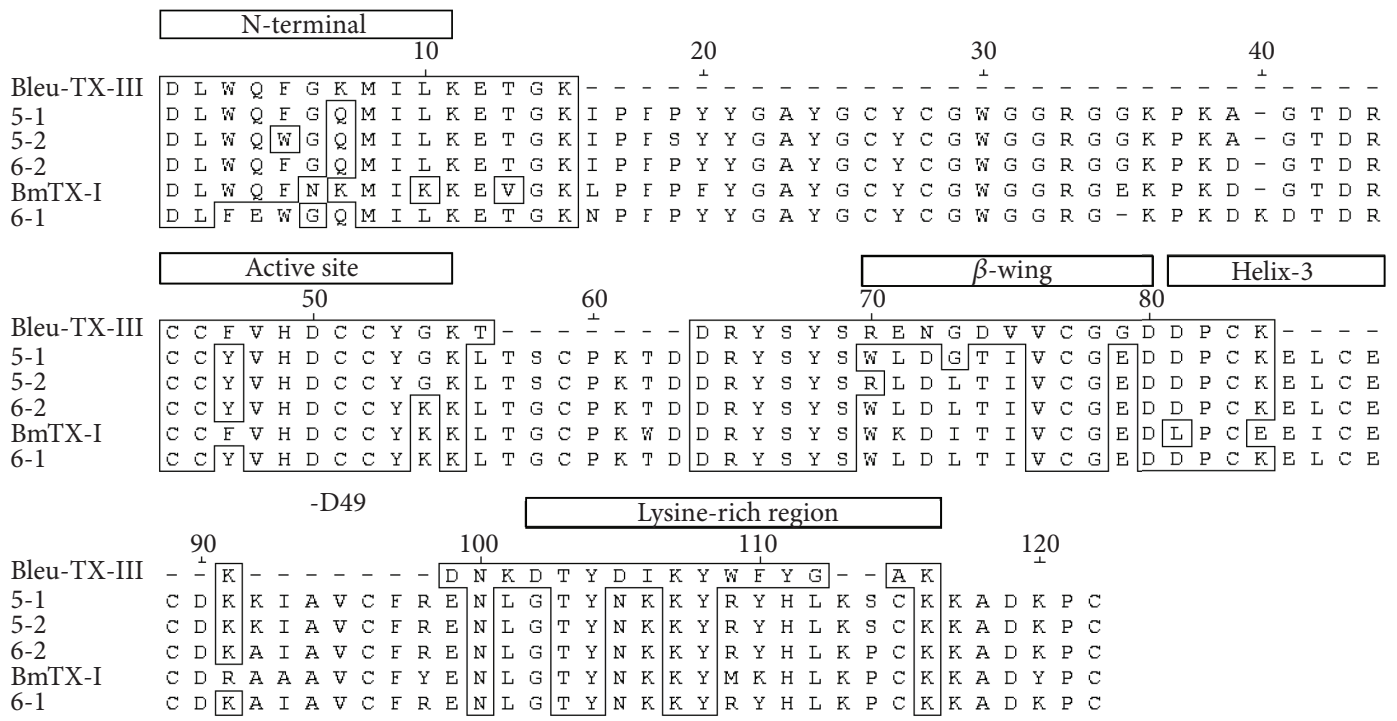

FIGURE 3: Alignment of the deduced amino acid sequence of the Bleu TX-III PLA 2 with D49-PLA_. 5_I and 5_II (BmjeTX-I and BmjeTX-II) from Bothrops marajoensis [28], 6_1 and 6_2 from Bothrops jararacussu [20] and BmTX-I from Bothrops moojeni [18].

for IL-1 and 3 hours for IL-6, respectively, (Figures 4(d) and 4(e)). Bleu TX-III caused a significant increase in the TNF- $\alpha$ concentrations only at $1 \mathrm{~h}$ (Figure $4(\mathrm{f})$ ).

\section{Discussion}

$\mathrm{PLA}_{2} \mathrm{~s}$ are among the most abundant components of snake venoms, showing a wide array of activities in spite of a conserved overall structure [19]. Understanding the structural basis for their diverse toxic activities, including myotoxicity and inflammatory, is still a challenging task. In this work, a new toxin was isolated, and structurally and functionally characterized, from Bothrops leucurus venom, showing that it belongs to the family of $\mathrm{PLA}_{2}$.

The purification procedure for basic $\mathrm{PLA}_{2} \mathrm{~s}$ developed $[9,20,21]$ is shown to be also efficient for the obtainment of the PLA $\mathrm{A}_{2}$ Bleu TX-III myotoxin from Bothrops leucurus snake venom. Fractionation protocol of this crude venom using a single pass chromatographic in a column $\mu$-Bondapack C-18 coupled to a system of reverse phase HPLC gave rise to 12 fractions at $280 \mathrm{~nm}$, the two last being the basic myotoxins, named Bleu TX-III PLA 2 (5). This rapid procedure showed high yield, producing 5-10 mg of the proteins with high purity levels (Figure 1(a)) and rechromatography of the major peak by RP-HPLC, what has yielded one main peak (Figure 1(a) inserted). The use of $\mathrm{NH}_{4} \mathrm{HCO}_{3}$ and acetonitrile (RPHPLC) as the buffer system is advantageous since these solvents are easily eliminated by lyophilization, thereby eliminating the need for desalting as in the case of ammonium bicarbonate.

The sequences of several tryptic peptides of peaks 2 and 4 (date not shown) were the same as described for P3 $(b l / \mathrm{K}$ $\mathrm{PLA}_{2}$ ) and P4 (bl/D49-PLA ${ }_{2}$ ) [8] (Figure 1(a)). Bleu TXIII was isolated to homogeneity by one chromatographic step. SDS-PAGE under nonreducing conditions showed that it occurs as a monomer, in the range of $\sim 14 \mathrm{kDa}$ after reduction (Figure 1(b) inserted). A subunit molecular mass of 14243.4297 Da was determined by ESI/MS mass spectrometry. The amino acid composition of the toxin revealed a high content of basic and hydrophobic residues, with 14 half-Cys, 


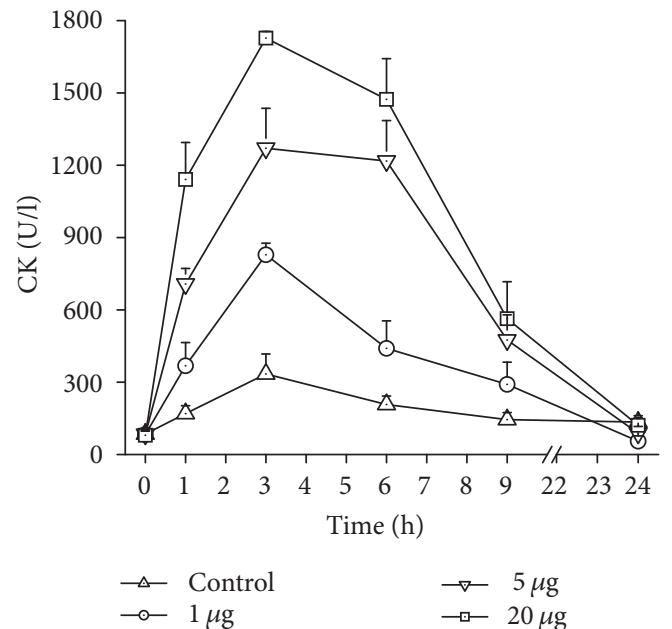

(a)

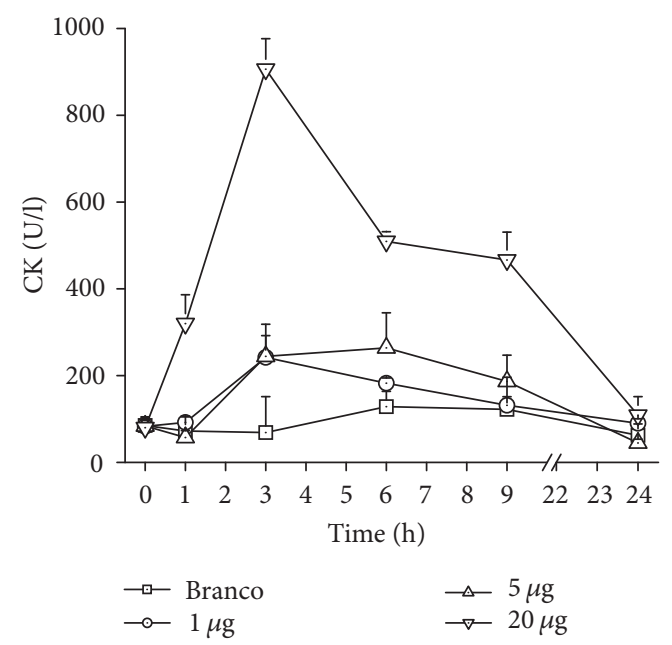

(b)

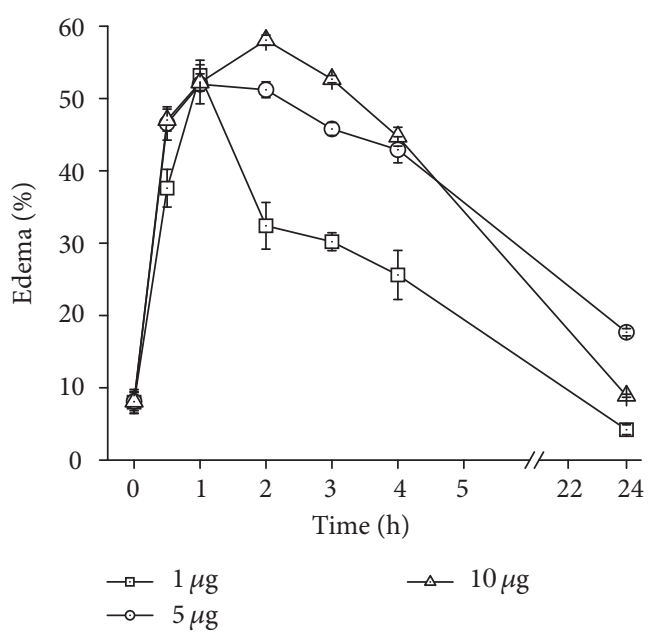

(c)

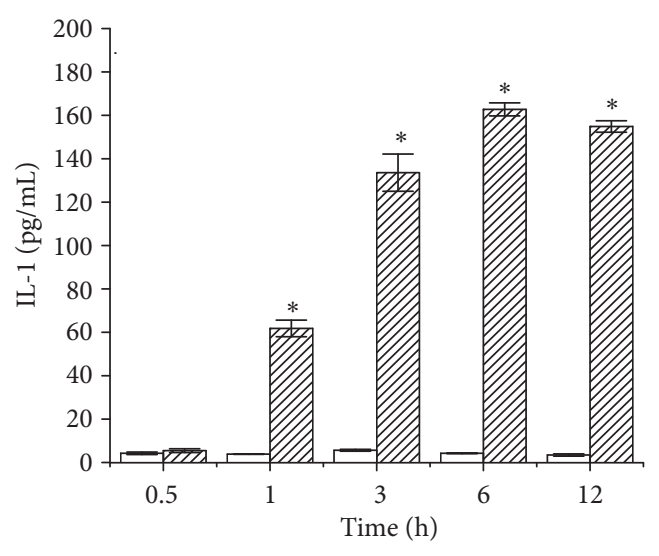

Control

EIJ Bleu TX-III

(d)

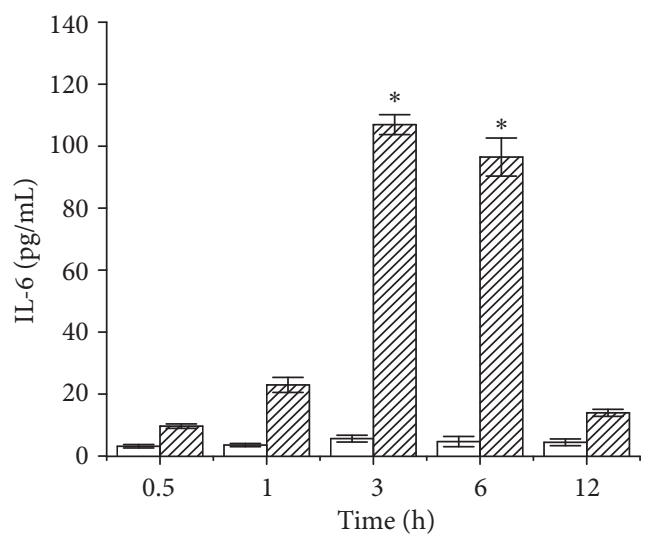

$\square$ Control

EII Bleu TX-III

(e)

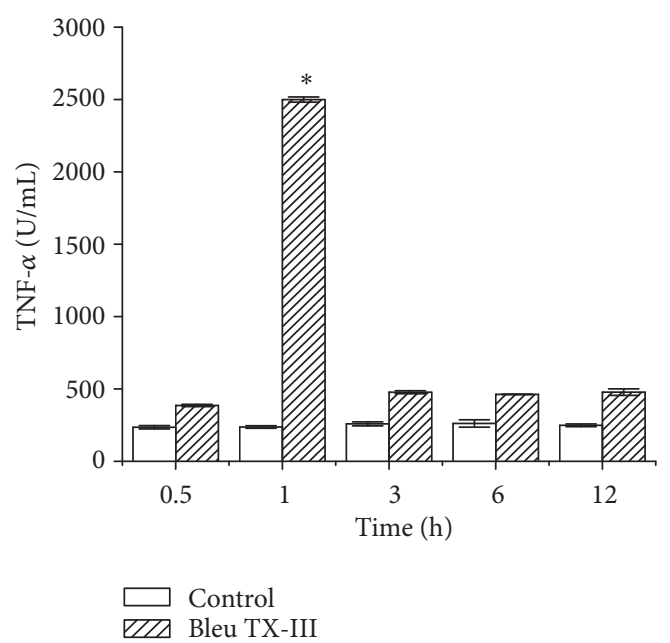

(f)

FIGURE 4: (a) and (b) Time-course of the increments in plasma CK activity after intramuscular injection and intravenous of Bleu TX-III $\mathrm{PLA}_{2}(1,5$, and $20 \mu \mathrm{g})$. Controls were injected with $100 \mu \mathrm{L}$ of PBS. At different times, blood was collected, and serum levels were measured. Values are means \pm SEM of five mice at each time point. (c) Edema-forming activity of Bleu TX-III PLA 2 (1, 5 and $20 \mu \mathrm{g})$. In mice. Induction

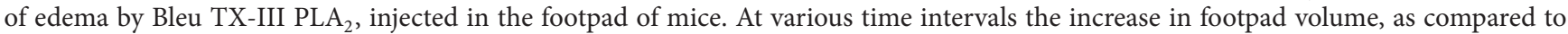
controls, was expressed as percent edema. Each point represents the mean \pm SEM of five animals. (d), (e), and (f) Cytokines levels in mice. The production of IL-1, IL-6, and TNF- $\alpha$ was assayed in plasma of Bleu TX-III PLA 2 . The experiments were performed in triplicate and analyzed statistically by ANOVA or Kruskal-Wallis tests and confirmed by Tukey and Tukey-type tests. Each point represents \pm SEM of seven mice $P<0.05$ between the experimental groups and control group. 
in agreement with the reported compositions and primary structures of myotoxic $\mathrm{PLA}_{2}$ s isolated from Bothrops venoms [9, 21-23].

This basic PLA $\mathrm{P}_{2}$ showed enzymatic activity on monodisperse substrate, with a strict requirement of $\mathrm{Ca}^{2+}$, and maximum activity at $\mathrm{pH} 8.0$ and $40^{\circ} \mathrm{C}$. These characteristics are common to other bothropic and crotalic $\mathrm{PLA}_{2} \mathrm{~S}$ $[21,24,25]$. The $\mathrm{PLA}_{2}$ activity is suggested to be higher in Bleu TX-III (16.22 $\pm 0.5268 \mathrm{nmols} / \mathrm{mim})$ and $b l / \mathrm{D}-49$ (4) $(15.728 \pm 0,3354 \mathrm{nmoles} / \mathrm{min})$ when compared with the whole venom $(3.617 \pm 0.4144 \mathrm{nmoles} / \mathrm{min})$ and $b l / \mathrm{K}-49$ $(2.856 \pm 0.464$ nmoles/min) (Figure $1(\mathrm{c}))$. The $\mathrm{Ca}^{2+}$ ion dependent on the enzymatic activity of Bleu TX-III revealed that the $\mathrm{Ca}^{2+}$ ion is an obligatory cofactor for its enzymatic activity. This can be explained by different coordination geometries assumed by the tetrahedral intermediate due to the presence of the $\mathrm{Ca}^{2+}$ ion which determine the electrophilic behavior of the catalytic site, as well as stabilizes the otherwise flexible $\mathrm{Ca}^{2+}$-binding loop and appears to optimize the interaction enzyme substrate [26].

Comparison of the N-terminal sequence of Bleu TX-III showed similarity with other myotoxic $\mathrm{PLA}_{2}$ from Bothrops genus (Figure 3).

To Bleu TX-III, no substitution was found in the conserved regions of the catalytic activity, as the channel hydrophobic N-terminal region (1 to 10 ) is important as a part of the interfacial bonding surface, so as active site (44 to 57) as suggested [26-28]. Considering the 7-peptides sequenced (this work), Bleu TX-III, showed high-level homology with many $\mathrm{PLA}_{2}$, from different snakes species. The highly conserved sequences XCGXGG and DXCCXXHD responsible for the $\mathrm{Ca}^{2+}$-binding loop and the catalytic site of $\mathrm{PLA}_{2}$ [29], respectively, are present in the sequence of $\mathrm{PLA}_{2}$ Bleu TX-III.

The P3 $\left(b l / \mathrm{K}-\mathrm{PLA} A_{2}\right), \mathrm{P} 4\left(b l / \mathrm{D}-\mathrm{PLA}_{2}\right)$, and fraction 5 (Bleu TX-III) enzymes seemed to be completely separated by reverse phase chromatography, and when some triptic peptides were sequenced by ESI/MS, of three PLA 2 , venom showed that Bothrops leucrurus have several homologous $\mathrm{PLA}_{2}$ and $\mathrm{PLA}_{2}$.

As a result of complications, mainly local edema and necrosis, usually occurred following ophidian accidents with Bothrops snakes $[30,31]$, and studies involving $\mathrm{PLA}_{2}$ s became very important, since they are the main venom components responsible for necrosis and inflammatory response [32].

Histological and ultrastructural studies of the effect of venom $\mathrm{PLA}_{2}$ s on skeletal muscle reveal a common series of pathological alterations which include (1) plasma membrane disruption, (2) formation of "delta-lesions," wedgeshaped areas of degeneration located at the periphery of muscle fibers, (3) hypercontraction of myofilaments, (4) mitochondrial swelling, together with the formation of flocculent densities and rupture of mitochondrial membranes, (5) disruption of intracellular membrane systems, that is, sarcoplasmic reticulum and $\mathrm{T}$ tubules, and (6) pycnosis of nuclei [32-35].

Our studies on local and systemic myotoxicity in vivo show that PLA 2 Bleu TX-III is not systemic myotoxins in the dose of $5 \mu \mathrm{g}$ and $20 \mu \mathrm{g}$ systemic slightly as local action due to decreased plasma levels of CK (Figures 4(a) and 4(b)). This reinforces the hypothesis of differential action of local and systemic myotoxicity proposed [32] and also the specificity and specificity proposed $[21,23,28]$.

The snake venom Bothrops induced local edema in humans and experimental animals [36]. Besides Bleu TXIII, a number of snake venom $\mathrm{PLA}_{2} \mathrm{~s}$, others also induce edema of 30 minutes after injection (Figure 3(c)) [4, 37, 38]. Studies have been conducted trying to understand the mechanisms involved in the inflammatory response induced by the myotoxic $\mathrm{PLA}_{2}$ from several snake venoms [30]. Studies have been directed trying to understand the mechanisms involved in the inflammatory response induced by myotoxic $\mathrm{PLA}_{2}$ from several snake venoms [39-41]. However, the relationship between enzymatic activity and edema is contradictory [42]. It is assumed that myotoxic and edematogenic activities can be induced by different structural domains in these $\mathrm{PLA}_{2}$, or that a partial overlapping of these domains occur [43].

Cytokines, such as IL-1, IL-6, and TNF- $\alpha$, are also relevant mediators for leukocyte migration and participate in several inflammatory conditions. Our results showed that $\mathrm{PLA}_{2}$ Bleu TX-III induced a stronger effect on the expression of adhesion molecules by endothelial cells and stimulates the release of both IL-1, IL-6, and TNF- $\alpha$ [44]. Thus, our results suggest that IL-1 may contribute for the leukocyte (Figures 3(d), 3(e), and 3(f)).

In conclusion, Bleu TX-III induces a marked inflammatory reaction in the mouse serum. Since basic myotoxic $\mathrm{PLA}_{2} \mathrm{~s}$ are abundant in snake venoms, these toxins must play a relevant role in the proinflammatory activity that characterizes this venom. The fact that Bleu TX-III elicited a stronger reaction inflammatory argues in favor of a role of enzymatic phospholipid hydrolysis in this phenomenon, either through the direct release of arachidonic acid from plasma membranes or through the activation of intracellular processes in target cells.

\section{Acknowledgments}

The authors acknowledge the Mass Spectrometry Laboratory at Brazilian Biosciences National Laboratory, CNPEMABTLUS, Campinas, Brazil, for their support with the mass spectrometric analyses. They also thank Daniel Martins-deSouza from Max Planck Institute of Psychiatry, Munich, Germany and Mr. Paulo A. Baldasso for general technical assistance. This work was supported by Capes and is a part of $\mathrm{Mg} \mathrm{Sc}$. thesis by F. A. Marangoni.

\section{References}

[1] J. J. Calvete, "Venomics: digging into the evolution of venomous systems and learning to twist nature to fight pathology," Journal of Proteomics, vol. 72, no. 2, pp. 121-126, 2009.

[2] J. W. Fox and S. M. T. Serrano, "Exploring snake venom proteomes: multifaceted analyses for complex toxin mixtures," Proteomics, vol. 8, no. 4, pp. 909-920, 2008. 
[3] D. Georgieva, R. K. Arni, and C. Betzel, "Proteome analysis of snake venom toxins: pharmacological insights," Expert Review of Proteomics, vol. 5, no. 6, pp. 787-797, 2008.

[4] F. Chaves, G. León, V. H. Alvarado, and J. M. Gutiérrez, "Pharmacological modulation of edema induced by Lys-49 and Asp-49 myotoxic phospholipases $A_{2}$ isolated from the venom of the snake Bothrops asper (terciopelo)," Toxicon, vol. 36, no. 12, pp. 1861-1869, 1998.

[5] D. C. S. Damico, S. Lilla, G. De Nucci et al., "Biochemical and enzymatic characterization of two basic Asp49 phospholipase $\mathrm{A}_{2}$ isoforms from Lachesis muta muta (Surucucu) venom," Biochimica et Biophysica Acta, vol. 1726, no. 1, pp. 75-86, 2005.

[6] R. Doley and R. M. Kini, "Protein complexes in snake venom," Cellular and Molecular Life Sciences, vol. 66, no. 17, pp. 2851-2871, 2009.

[7] D. C. O. Nunes, R. S. Rodrigues, M. N. Lucena et al., "Isolation and functional characterization of proinflammatory acidic phospholipase $\mathrm{A}_{2}$ from Bothrops leucurus snake venom," Comparative Biochemistry and Physiology C, vol. 154, no. 3, pp. 226-233, 2011.

[8] D. A. Higuchi, C. M. V. Barbosa, C. Bincoletto et al., "Purification and partial characterization of two phospholipases $\mathrm{A}_{2}$ from Bothrops leucurus (white-tailed-jararaca) snake venom," Biochimie, vol. 89, no. 3, pp. 319-328, 2007.

[9] L. A. Ponce-Soto, P. A. Baldasso, F. F. Romero-Vargas, F. V. Winck, J. C. Novello, and S. Marangoni, "Biochemical, pharmacological and structural characterization of two $\mathrm{PLA}_{2}$ isoforms Cdr-12 and Cdr-13 from Crotalus durissus ruruima snake venom," Protein Journal, vol. 26, no. 1, pp. 39-49, 2007.

[10] H. Schagger and G. Von Jagow, "Tricine-sodium dodecyl sulfate-polyacrylamide gel electrophoresis for the separation of proteins in the range from 1 to $100 \mathrm{kDa}$," Analytical Biochemistry, vol. 166, no. 2, pp. 368-379, 1987.

[11] M. Holzer and S. P. Mackessy, "An aqueous endpoint assay of snake venom phospholipase $\mathrm{A}_{2}$," Toxicon, vol. 34, no. 10, pp. 1149-1155, 1996.

[12] L. A. Ponce-Soto, M. H. Toyama, S. Hyslop, J. C. Novello, and S. Marangoni, "Isolation and preliminary enzymatic characteriza-

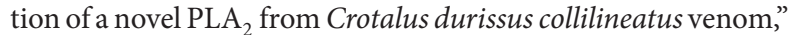
Journal of Protein Chemistry, vol. 21, no. 3, pp. 131-136, 2002.

[13] R. L. Hendrickson and S. C. Meredith, "Amino acid analysis by reverse-phase high-performance liquid chromatography: precolumn derivatization with phenylisothiocyanate," Analytical Biochemistry, vol. 136, pp. 65-74, 1984.

[14] J. H. Schumaker, A. OGarra, B. Schrader et al., "The characterization of four monoclonal antibodies specific for mouse IL-5 and development of mouse and human IL-5 ELISA," The Journal of Immunology, vol. 141, pp. 1576-1581, 1988.

[15] M. R. Ruff and G. E. Gifford, "Purification and physicochemical characterization of rabbit tumor necrosis factor," Journal of Immunology, vol. 125, no. 4, pp. 1671-1677, 1980.

[16] T. R. John, L. A. Smith, and I. I. Kaiser, "Genomic sequences encoding the acidic and basic subunits of Mojave toxin: unusually high sequence identity of non-coding regions," Gene, vol. 139, no. 2, pp. 229-234, 1994.

[17] H. M. Verheij, J. Westerman, B. Sternby, and G. H. de Haas, “The complete primary structure of phospholipase $\mathrm{A}_{2}$ from human pancreas," Biochimica et Biophysica Acta, vol. 747, no. 1-2, pp. 93-99, 1983.
[18] A. K. Calgarotto, D. C. S. Damico, L. A. Ponce-Soto et al., "Biological and biochemical characterization of new basic phospholipase $\mathrm{A}_{2}$ BmTX-I isolated from Bothrops moojeni snake venom," Toxicon, vol. 51, no. 8, pp. 1509-1519, 2008.

[19] E. Valentin and G. Lambeau, "What can venom phospholipases $\mathrm{A}_{2}$ tell us about the functional diversity of mammalian secreted phospholipases $\mathrm{A}_{2}$ ?” Biochimie, vol. 82, no. 9-10, pp. 815-831, 2000.

[20] L. A. Ponce-Soto, V. L. Bonfim, L. Rodrigues-Simioni, J. C. Novello, and S. Marangoni, "Determination of primary structure of two isoforms 6-1 and 6-2 PLA 2 D49 from Bothrops jararacussu snake venom and neurotoxic characterization using in vitro neuromuscular preparation," Protein Journal, vol. 25, no. 2, pp. 147-155, 2006.

[21] L. A. Ponce-Soto, J. C. Barros, S. Marangoni et al., "Neuromuscular activity of BaTX, a presynaptic basic $\mathrm{PLA}_{2}$ isolated from Bothrops alternatus snake venom," Comparative Biochemistry and Physiology C, vol. 150, no. 2, pp. 291-297, 2009.

[22] J. Gutiérrez and B. Lomonte, "Phospholipase $A_{2}$ myotoxins from Bothrops snake venoms," Toxicon, vol. 33, no. 11, pp. 1405-1424, 1995.

[23] R. M. Kini, "Excitement ahead: structure, function and mechanism of snake venom phospholipase $\mathrm{A}_{2}$ enzymes," Toxicon, vol. 42, no. 8, pp. 827-840, 2003.

[24] S. Huancahuire-Vega, L. A. Ponce-Soto, D. Martins-de-Souza, and S. Marangoni, "Structural and functional characterization of brazilitoxins II and III (BbTX-II and -III), two myotoxins from the venom of Bothrops brazili snake," Toxicon, vol. 54, no. 6, pp. 818-827, 2009.

[25] J. A. Pereañez, V. Núñez, S. Huancahuire-Vega, S. Marangoni, and L. A. Ponce-Soto, "Biochemical and biological characterization of a PLA 2 from crotoxin complex of Crotalus durissus cumanensis," Toxicon, vol. 53, no. 5, pp. 534-542, 2009.

[26] D. L. Scott, S. P. White, Z. Otwinowski, W. Yuan, M. H. Gelb, and P. B. Sigler, "Interfacial catalysis: the mechanism of phospholipase A $A_{2}$, Science, vol. 250, no. 4987, pp. 1541-1546, 1990.

[27] R. K. Arni and R. J. Ward, "Phospholipase $\mathrm{A}_{2}$-a structural review," Toxicon, vol. 34, no. 8, pp. 827-841, 1996.

[28] L. A. Ponce-Soto, D. Martins-De-souza, and S. Marangoni, "Neurotoxic, myotoxic and cytolytic activities of the new basic $\mathrm{PLA}_{2}$ isoforms BmjeTX-I and BmjeTX-II isolated from the Bothrops marajoensis (marajó lancehead) snake venom," Protein Journal, vol. 29, no. 2, pp. 103-113, 2010.

[29] R. Renetseder, S. Brunie, B. W. Dijkstra, J. Drenth, and P. B. Sigler, "A comparison of the crystal structure of phospholipase $\mathrm{A}_{2}$ from bovine pancreas and Crotalus atrox venom," Journal of Biological Chemistry, vol. 260, no. 21, pp. 11627-11634, 1985.

[30] J. M. Gutiérrez, "Understanding snake venoms: 50 years of research in Latin America," Revista De Biologia Tropical, vol. 50, no. 2, pp. 377-394, 2002.

[31] A. S. Kamiguti, J. L. C. Cardoso, R. D. G. Theakston et al., "Coagulopathy and haemorrhage in human victims of Bothrops jararaca envenoming in Brazil," Toxicon, vol. 29, no. 8, pp. 961-972, 1991.

[32] J. M. Gutiérrez and C. L. Ownby, "Skeletal muscle degeneration induced by venom phospholipases A 2: insights into the mechanisms of local and systemic myotoxicity," Toxicon, vol. 42, no. 8, pp. 915-931, 2003.

[33] J. M. Gutierrez, C. L. Ownby, and G. V. Odell, "Skeletal muscle regeneration after myonecrosis induced by crude venom and 
a myotoxin from the snake Bothrops asper (Fer-de-Lance)," Toxicon, vol. 22, no. 5, pp. 719-731, 1984.

[34] J. B. Harris and M. J. Cullen, "Muscle necrosis caused by snake venoms and toxins," Electron Microscopy Reviews, vol. 3, no. 2, pp. 183-211, 1990.

[35] D. Mebs and C. L. Ownby, "Myotoxic components of snake venoms: their biochemical and biological activities," Pharmacology and Therapeutics, vol. 48, no. 2, pp. 223-236, 1990.

[36] J. M. Gutiérrez, F. Chaves, and L. Cerdas, "Inflammatory infiltrate in skeletal muscle injected with Bothrops asper venom," Revista de Biologia Tropical, vol. 34, no. 2, pp. 209-214, 1986.

[37] D. F. J. Ketelhut, M. Homem De Mello, E. L. G. Veronese et al., "Isolation, characterization and biological activity of acidic phospholipase $\mathrm{A}_{2}$ isoforms from Bothrops jararacussu snake venom," Biochimie, vol. 85, no. 10, pp. 983-991, 2003.

[38] R. S. Rodrigues, L. F. M. Izidoro, S. S. Teixeira et al., "Isolation and functional characterization of a new myotoxic acidic phospholipase $\mathrm{A}_{2}$ from Bothrops pauloensis snake venom," Toxicon, vol. 50, no. 1, pp. 153-165, 2007.

[39] E. C. T. Landucci, R. C. Castro, M. F. Pereira et al., "Mast cell degranulation induced by two phospholipase $\mathrm{A}_{2}$ homologues: dissociation between enzymatic and biological activities," European Journal of Pharmacology, vol. 343, no. 2-3, pp. 257-263, 1998.

[40] E. C. T. Landucci, R. C. De Castro, M. Toyama et al., "Inflammatory oedema induced by the Lys- 49 phospholipase $A_{2}$ homologue piratoxin-I in the rat and rabbit. Effect of polyanions and p-bromophenacyl bromide," Biochemical Pharmacology, vol. 59, no. 10, pp. 1289-1294, 2000.

[41] B. Lomonte, A. Tarkowski, and L. A. Hanson, "Host response to Bothrops asper snake venom. Analysis of edema formation, inflammatory cells, and cytokine release in a mouse model," Inflammation, vol. 17, no. 2, pp. 93-105, 1993.

[42] B. S. Vishwanath, R. M. Kini, and T. V. Gowda, "Characterization of three edema-inducing phospholipase $\mathrm{A}_{2}$ enzymes from habu (Trimeresurus flavoviridis) venom and their interaction with the alkaloid aristolochic acid," Toxicon, vol. 25, no. 5, pp. 501-515, 1987.

[43] J. P. Zuliani, C. M. Fernandes, S. R. Zamuner, J. M. Gutiérrez, and C. F. P. Teixeira, "Inflammatory events induced by Lys49 and Asp-49 phospholipases $A_{2}$ isolated from Bothrops asper snake venom: role of catalytic activity," Toxicon, vol. 45 , no. 3 , pp. 335-346, 2005.

[44] E. Stylianou and J. Saklatvala, "Interleukin-1," International Journal of Biochemistry and Cell Biology, vol. 30, no. 10, pp. 1075-1079, 1998. 

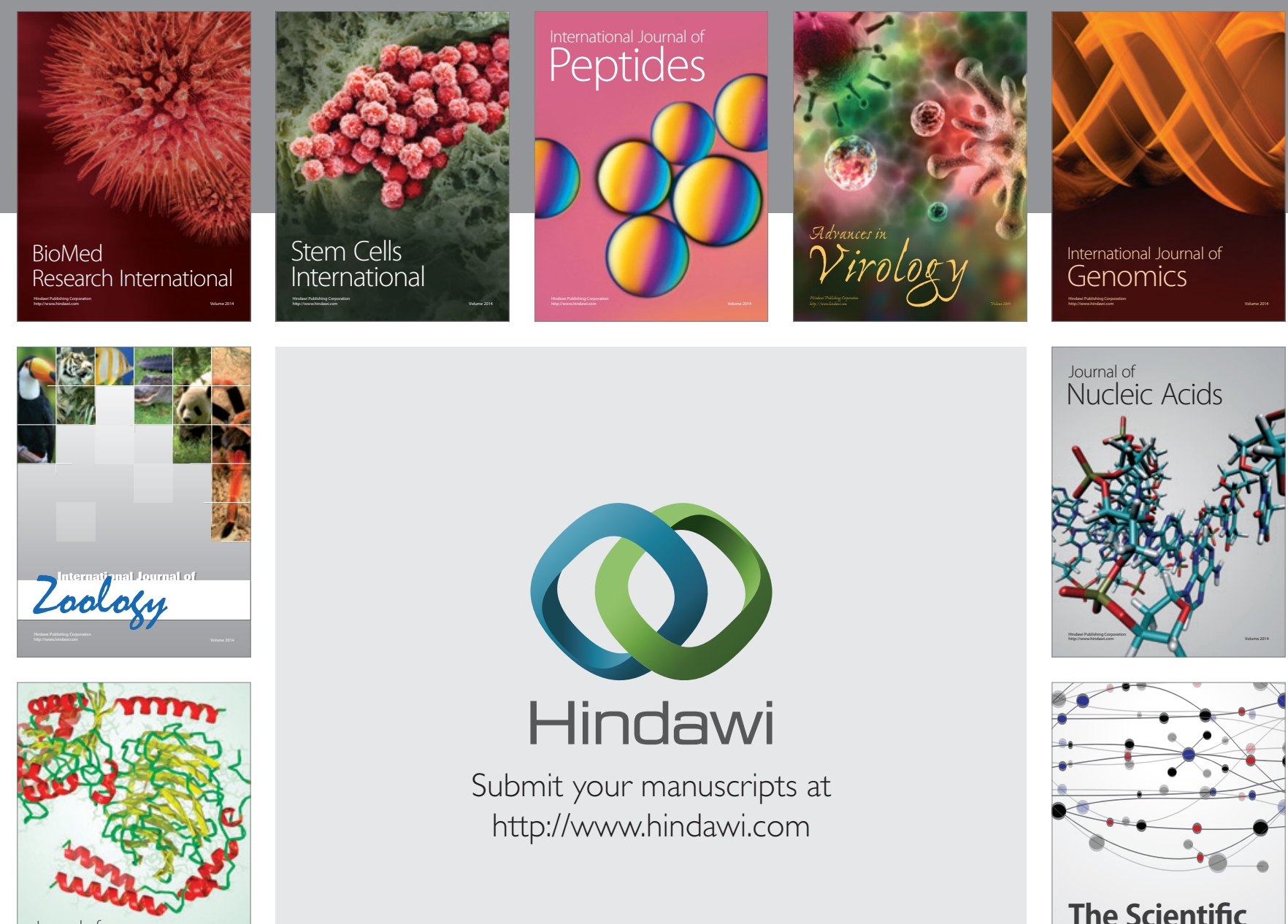

Submit your manuscripts at

http://www.hindawi.com

Journal of
Signal Transduction
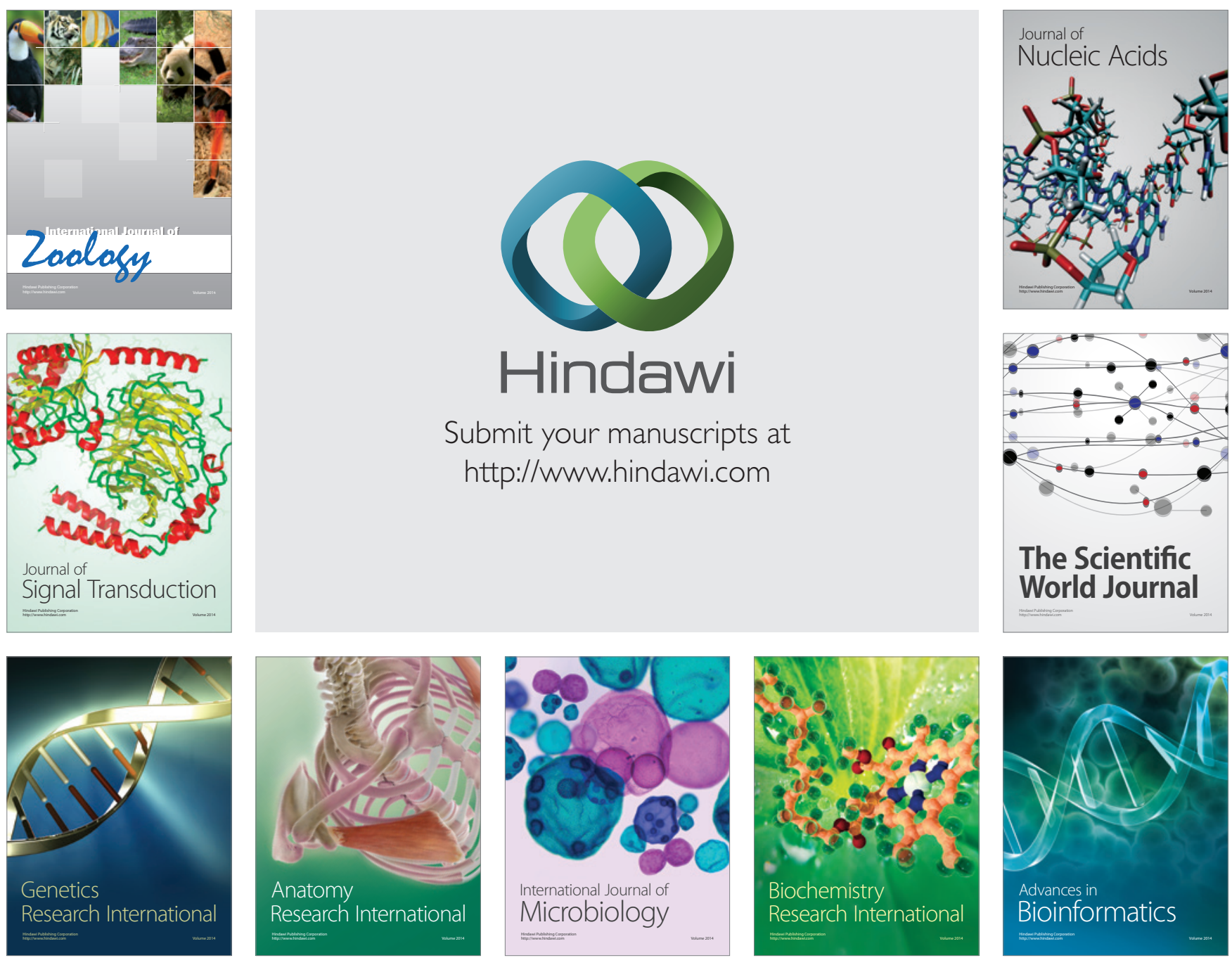

The Scientific World Journal
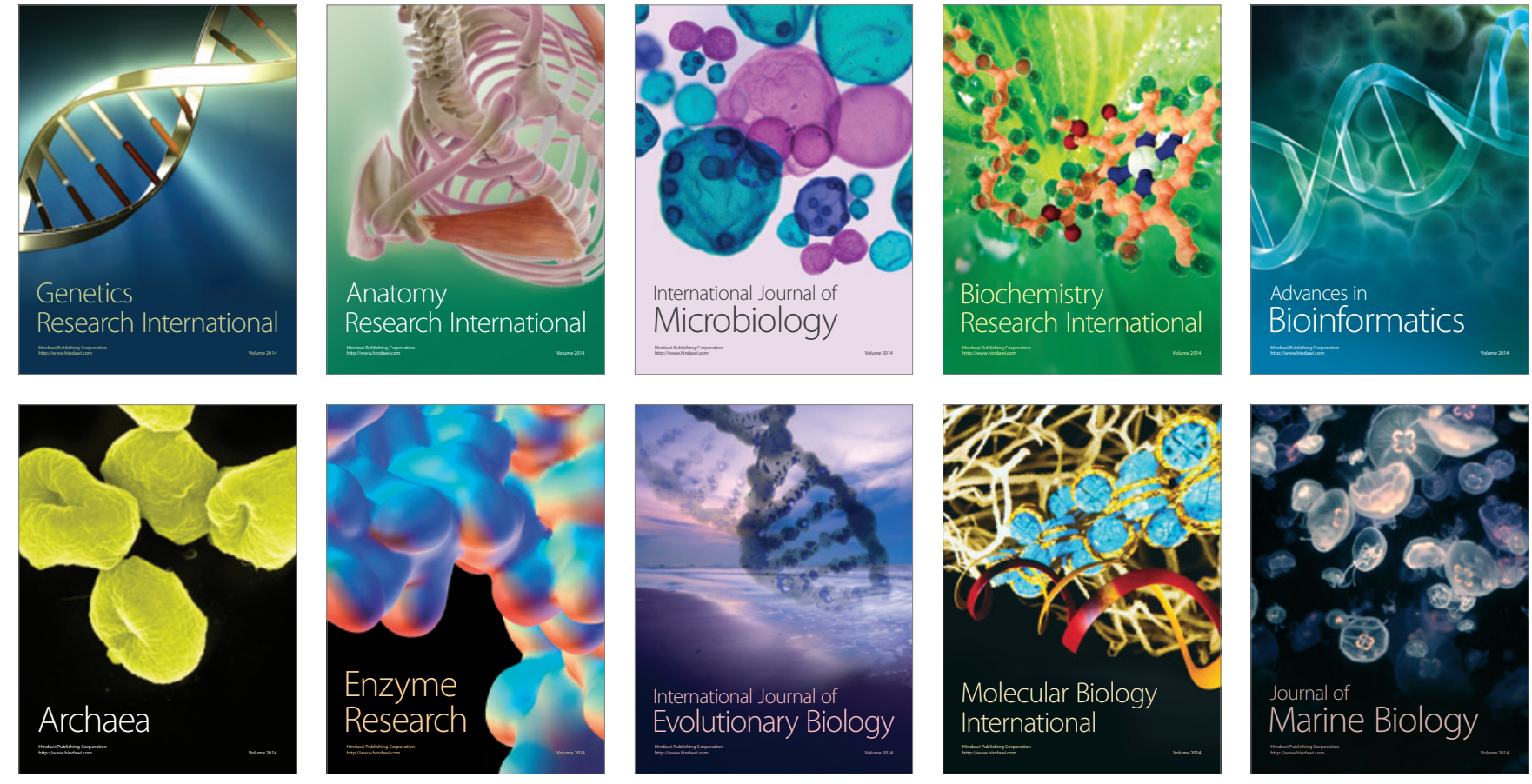